\title{
20 \\ VIOLENCE AND CLIMATE CHANGE IN THE JŌMON PERIOD, JAPAN
}

\author{
Hisashi Nakao, Tomomi Nakagawa, Kohei Tamura, Yuji Yamaguchi, \\ Naoko Matsumoto, and Takehiko Matsugi
}

\section{Introduction}

There is wide agreement that climate change has significantly impacted various aspects of human life throughout history. Recent global warming, it is commonly pointed out, may result in devastating consequences including frequent droughts and the submergence of coastal areas due to rising sea-levels (IPCC, 2013-2014). Prehistoric data also suggest that past lives were strongly influenced by climate change. Almost all scholars agree that lower sea-levels during the last glacial period allowed humans to migrate into previously uninhabited environments, to enter the Japanese archipelago and the New World, for example. Climate change has also caused fundamental societal changes (Dougals et al., 2015; Hoggath et al., 2016); for Japan, a vast amount of literature suggests that climate change has modified lifestyle elements and created challenges that inspired technological innovations such as pottery and stone projectile points (e.g., Anzai, 2014; Kawahata et al., 2017; Morisaki et al., 2015; 2018; Sato and Morisaki, 2011).

Climate change can be an important causal factor for change in human social activities. Some researchers have argued that climate change and warfare have also been closely connected over time and they predict that violent responses will be common in the future (e.g., Ember and Ember, 1992; Hsiang et al., 2011; Keeley, 1996; Meyer et al., 2015; Otterbein, 2004; Scheffran et al., 2012; Zhang et al., 2007). One postulated mechanism involves a lack of food; climate change alters local environments, potentially leading to shortages in environmentally dependent food sources. The transition from the cool, dry climate of the last glacial period to the warm interglacial period has been blamed for the extinction of large mammals, although recent studies suggest that the spread of Homo sapiens was the main cause of global size-biased extinction (Smith et al., 2018). Otterbein (2004, pp. 66-68) argued that such a decrease in numbers of big game was an important cause of an increase in violence among prehistoric hunter-gatherers. Meyer et al. (2015, p. 11221) also suggested that frequent warfare found in the LBK culture of Neolithic Europe had been caused partly by climate change events such as drought. Keeley (1996, p. 140, italics added) seems to consider climate change a dominant cause of the frequent occurrence of warfare, saying, "it is becoming increasingly certain that many prehistoric cases of intensive warfare in various regions correspond with hard times created by ecological and climatic changes."While it is clear that some recent civil conflicts have been strongly influenced by global 
climate change and climate change can promote or contribute to warfare in industrialized societies (Hsiang et al., 2011), it should be noted that different socio-cultural systems react differently under similar environmental conditions.

This chapter aims to investigate the effect of climate change in Japanese prehistory, especially on Jōmon culture and society. We review and summarize research on the effect of climate change on Jomon culture and society in the Japanese archipelago, showing that climate change was probably relevant to many aspects of Jōmon society, especially to decreases in population and the number of large settlements at the end of the Middle Jomon sub-period. We then demonstrate there is very little evidence for violent behavior during the Jomon period based on exhaustive bioarchaeological data, suggesting that climate change did not promote violence in the period. Finally, we discuss why climate change was not a significant cause of violent behavior in this period.

\section{Climate change in the Jōmon period}

After a brief introduction to the basic character of the Jōmon period, this section summarizes the climate change of this period and its effect on Jōmon culture and society. In particular, we argue that climate change was probably relevant to decreases in population and large settlements in eastern Japan, which started at the end of the Middle Jōmon.

The subsistence system in the Jomon period $(13,000-800 \mathrm{cal} \mathrm{BC})$ was based on hunting and gathering, though Jōmon populations were not stereotypical foragers in having a certain level of sedentariness (especially after the late phase of the Incipient Jomon sub-period) and in making pottery (Habu, 2004; Imamura, 2000; Matsumoto et al., 2017). The Jōmon was preceded by

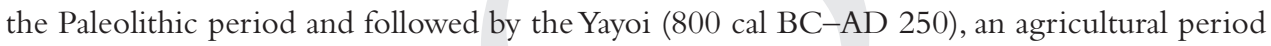
when warfare (or large-scale intergroup conflict) probably began in the Japanese archipelago (Nakagawa et al., 2017, n.d.; Sahara, 1986; Hashiguchi, 2007). The Jōmon period is composed of six sub-periods: Incipient (13,000-10,000 cal BC), Initial (10,000-5000 cal BC), Early (5000$3500 \mathrm{cal} \mathrm{BC}$ ), Middle (3500-2400 cal BC), Late (2400-1250 cal BC), and Final (1250-800 cal $\mathrm{BC})$. Because this chapter aims to explore the relationship between climate change and violence in terms of bioarchaeology, but no human skeletal remains have been found for the Incipient Jömon, we skip that sub-period in the following discussion.

Climate change as estimated for the Jōmon period generally parallels global trends. During the Holocene Climatic Optimum (9000-5000 BP), warming climate and rising sea-levels created a productive environment for hunter-gatherers in the Japanese archipelago in which large settlements and shell middens formed from the latter half of the Initial Jomon to the early phase of the Middle Jōmon. Kudo (2012, pp. 109-110) suggests a cooling climate ensued after the latter half of the Middle Jomon, possibly leading to the $4.2 \mathrm{ka}$ event, a globally identified severe cooling period (deMenocal, 2001). The effects of climate change on sociocultural and ecological aspects of this period have been a major issue in Japanese archaeology, including changes to material culture like pottery-making, projectile point production, population growth or decline, and degrees of sedentism (e.g., Anzai, 2014; Habu, 2004; Habu and Hall, 2013; Kawahata et al., 2017; Kosugi et al., 2009; 2010; Kudo, 2012; Matsui, 2005; Morisaki et al., 2015, 2018; Sato and Morisaki, 2011).

The Jōmon period has received much attention from scholars because climate change in that period was varticularly dramatic. First, due to rising sea-levels after the Last Glacial Maximum, the Japanes ar hipelago was completely separated from the Eurasian continent in the Incipient Jomon. Subsequently,the sea level fluctuated three to four meters throughout the Jomon period; however, the timing and degree of sea-level changes were extremely varied across the 


\section{H. Nakao et al.}

Table 20.1 Koyama's (1984) population estimation. Numbers in parentheses are population density per $\mathrm{km}^{2}$.

\begin{tabular}{lrrrrr}
\hline Phase & \multicolumn{1}{l}{ Initial } & \multicolumn{1}{c}{ Early } & \multicolumn{1}{l}{ Middle } & \multicolumn{1}{l}{ Late } & \multicolumn{1}{c}{ Final } \\
\hline Tr liol u & $2,000(0.03)$ & $19,200(0.29)$ & $46,700(0.07)$ & $43,800(0.65)$ & $39,600(0.59)$ \\
Kanoto & $9,700(0.30)$ & $42,800(1.34)$ & $95,400(2.98)$ & $51,600(1.61)$ & $7700(0.24)$ \\
Hokuriku & $400(0.02)$ & $4200(0.17)$ & $24,600(0.98)$ & $15,700(0.63)$ & $5100(0.20)$ \\
Chubu & $3000(0.10)$ & $25,300(0.84)$ & $71,900(2.40)$ & $22,000(0.73)$ & $6000(0.20)$ \\
Tokai & $2200(0.16)$ & $5000(0.36)$ & $13,200(0.94)$ & $7600(0.54)$ & $6600(0.47)$ \\
Kinki & $300(0.01)$ & $1700(0.05)$ & $2800(0.09)$ & $4400(0.14)$ & $2100(0.07)$ \\
Chugoku & $400(0.01)$ & $1300(0.04)$ & $1200(0.04)$ & $2400(0.07)$ & $2000(0.06)$ \\
Shikoku & $200(0.01)$ & $400(0.02)$ & $200(0.01)$ & $2700(0.14)$ & $500(0.03)$ \\
Kyushu & $1900(0.05)$ & $5600(0.13)$ & $5300(0.13)$ & $10,100(0.24)$ & $6300(0.15)$ \\
Total & $20,100(0.07)$ & $105,500(0.36)$ & $261,300(0.89)$ & $160,300(0.55)$ & $75,800(0.26)$ \\
\hline
\end{tabular}

archipelago (Habu, 2004; Kudo, 2012; Tomioka, 2010). For instance, the Kanto area saw a 2.5meter peak above the present sea level around $4000 \mathrm{cal} \mathrm{BC}$, sea-level rise peaked at 1.5 meters around $1550 \mathrm{cal} \mathrm{BC}$ at Matsushima bay in Tohoku, and Okayama in the Chugoku district saw a 3-meter fluctuation in sea level from 2050 to 1000 cal BC (Fujimoto, 1990; Hitoki, 2012; Kudo 2012; Suzuki, 2005).

Such dramatic changes directly affected activities in Jōmon society. For instance, the significant marine transgression in areas such as Kanto in the Initial and Early Jomon sub-periods (sometimes called the "Jōmon Transgression") is associated with an accelerated use of marine resources (Uetsuki, 2010). Under the warming climate, boreal conifer forests receded to the north and higher altitudes while deciduous broadleaf and evergreen forests expanded, providing a wider variety of seeds and nuts (Habu, 2004). Although evergreen forests covered most of the western part of the Japanese archipelago and advanced in the eastern part of the archipelago during the climatic optimum (Tsuji, 2009), deciduous broadleaf forests dominated in the eastern part of the archipelago on the whole. Population size increased significantly and sedentary settlements developed in the deciduous broadleaf forests of the eastern part of the archipelago; the western part did not experience population growth, intensification of subsistence, and social complexity in the same way, which some have speculated was related to the thick evergreen forest ecosystem (Matsumoto et al., 2017).

Climate cooled at the end of the Middle Jōmon, corresponding to a decline in population size and the collapse of large settlements in the eastern part of the Japanese archipelago. According to Koyama's $(1978 ; 1984)$ calculation of the number of sites in the Jomon period, a peak in site numbers - and thus inferred population sizes - is seen in the eastern part of the archipelago in the Middle Jōmon, followed by a radical decline after that sub-period (see Table 20.1). Imamura (1997) also counted the number of dwellings in the Kanto and Chubu areas of the Jōmon period to investigate population dynamics more closely; the results are consistent with Koyama's calculation (see Figure 20.1).

In the eastern part of the archipelago, large settlements such as the Sannai Maruyama site (see also below) disappeared at the end of the Middle Jomon (Abe, 2008; Kanno, 2017; Matsumoto, 2018a). Based on these observations, climate change has been blamed for population size declines and the collapse of large settlements at the end of this period (e.g., Kodama, 2003; Okada, 2003; Yasuda, 1989); however, a considerable amount of climate data suggest sea levels 


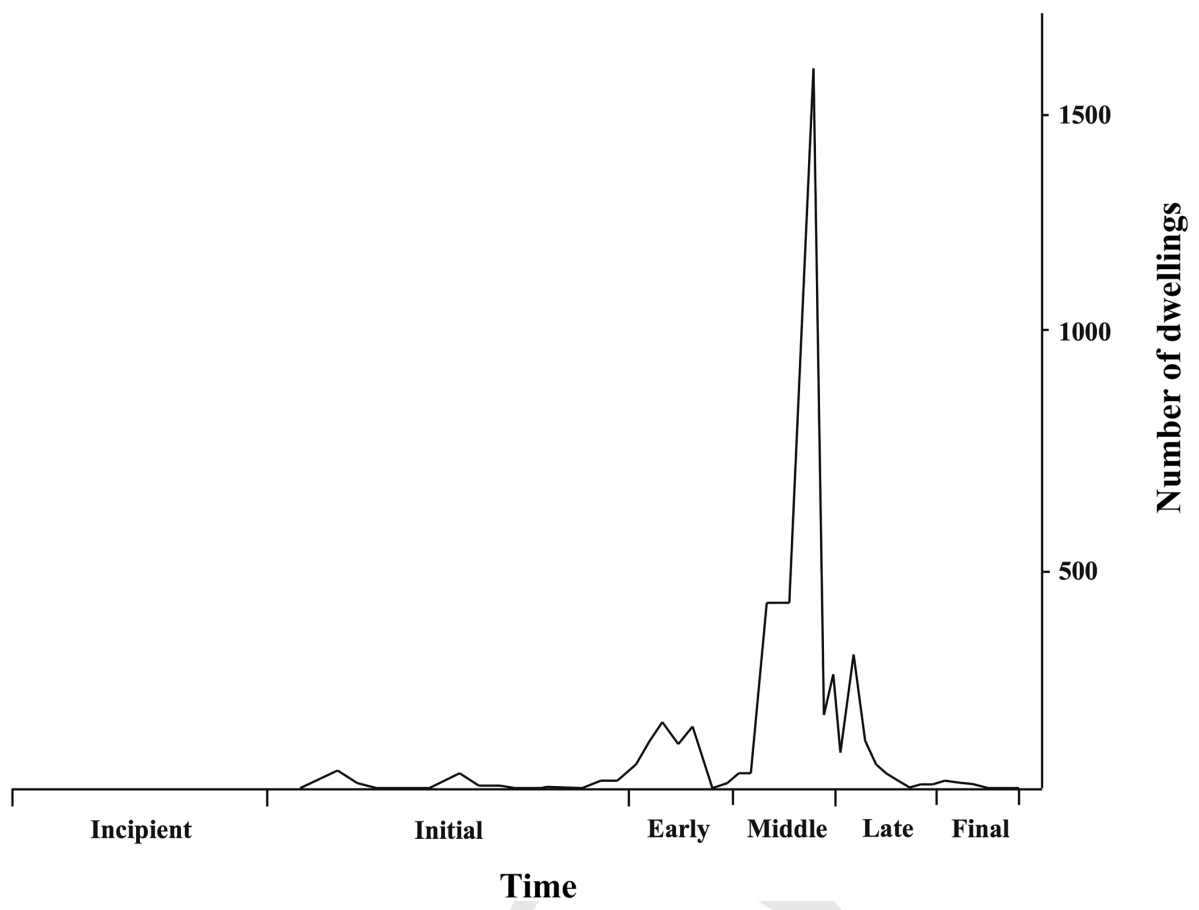

Figure 20.1 The number of dwellings in the southeastern Kanto area per 100 years.

From Imamura, 1997.

had regressed and the climate was already much cooler than the Initial and Early Jōmon subperiods (e.g., Habu, 2004; Tsuji, 2009).

Habu (2008; Habu and Hall, 2013) has proposed a more specific relationship between population decline and cooling climate in the late phase of the Middle Jōmon. She focuses especially on the Sannai Maruyama site, located in the northern part of Aomori prefecture, which continued from the middle phase of the Early to the late phase of the Middle Jomon subperiod. Her analysis of the stone tool assemblage, the number of dwellings, and clay figurines at the site suggested an overdependence on a particular plant food resulted in a loss of variety in subsistence and an increase in vulnerability, so that a short-term fluctuation in climate may have significantly impacted the population and society (Habu, 2017). The stone tool assemblage had become dominated by grinding stones and the numbers of dwellings and clay figurines decreased in the latter half of the Middle Jomon (c. $4800 \mathrm{cal} \mathrm{BC}$ ), significantly earlier than the $4.2 \mathrm{ka}$ event. A similar explanation could account for population size declines and large settlement collapses in other parts of the Japanese archipelago in the late phase of the Middle Jomon.

Social factors were certainly partly responsible for the major declines in population and large settlement numbers at this time. A certain level of social stratification for Jōmon society has been assumed (e.g., Hayden, 1995; Sasaki, 2000; Taniguchi, 2017; Watanabe, 1990). It has also been suggested that tension between two conflicting social norms-common ownership and family ownership - helped trigger the social collapse at the end of the Middle Jomon (Sasaki, 2000). While we would need more evidence to support such a hypothesis for social change, it should be noted that this possibility does not contradict previous claims for the effect of climate 


\section{H. Nakao et al.}

change in the late phase of the Middle Jōmon sub-period. Current evidence supports a role for climate change in changing human activities of the Jōmon period, though we should continue to investigate more specific mechanisms to explain how climate change influenced culture and society. Next, we consider whether climate change also affected violent conflict in the period.

\section{Skeletal remains in the Jōmon period}

There is little bioarchaeological evidence for violence during the Jomon period, suggesting that while climate change corresponds to visible changes in population size, organization, subsistence practices, and material culture for the period outlined above, violence is not a foregone conclusion for human communities facing extreme changes in environmental circumstances. Detailed bioarchaeological data during the period were summarized by Yamada (2006), who examined over 2500 skeletal remains to estimate age at death, mortuary $\mathrm{p}$ ssit oning or posture, and skeletal injuries. Using Yamada's exhaustive data set, Nakao et al. $(2010 a$; b ) calculater th: rate of injured skeletal remains (see Table 20.2 and supplementary data in Nakao et al., 2016a, for details) and plotted these data on a map of the Japanese archipelago (see Figure 20.2). Results of that analysis indicate the rate of injured skeletal remains is much lower than the rates calculated in previous studies including relevant data in different areas (e.g., Bowles, 2009; Keeley, 1996; Pinker, 2011), ind hat sites with injured skeletal remains were spatiotemporally scattered. Nakao et al. (2016a, v) argued that violence was not frequent during the hunting and gathering period in the Japanese archipelago and this low rate of violent conflict was relatively stable over the Jomon period.

Bioarchaeological data for the Yayoi period provide context for assessing Nakao and colleagues' (2016) claim. As already mentioned, it has been commonly pointed out that warfare or inter-group violence began in the Yayoi period (e.g., Hashiguchi, 2007; Matsugi, 2007; 2017; Sahara, 1986). Nakagawa and colleagues $(2017 ; 2019)$ and Nakagawa (2020) used the same method as Nakao and colleagues (2016) to calculate the rate of injuries among the Yayoi period skeletal remains and statistically compared them (for details see Table 20.3 below, and the supplementary data in Nakagawa et al., 2017). The results show a statistically significant increase in evidence for violent conflict over time, supporting Nakao and colleagues' (2016) claim that violence was low for the hunting and gathering period in the Japanese archipelago.

The bioarchaeological data for the Jomon period, and the lack of fortifications or other evidence for violent interactions (e.g., Sahara, 1986; Matsugi, 2007; 2017), suggest that significant

Tab $=2$ Estimates of mortality attributable to violence over the Jōmon period (see also Nakao et al., 2016a).

\begin{tabular}{|c|c|c|c|c|c|c|}
\hline Phase & Total & Adults & $I D$ & $\begin{array}{l}\text { ID without } \\
\text { children }\end{array}$ & $\begin{array}{l}\text { ID/total } \\
(\%)\end{array}$ & $\begin{array}{l}\text { ID without } \\
\text { children/adults(\%) }\end{array}$ \\
\hline Initial & 113 & 39 & 1 & 1 & $0.89 \%$ & $2.56 \%$ \\
\hline Early & 216 & 117 & 0 & 0 & $0.00 \%$ & $0.00 \%$ \\
\hline Middle & 371 & 172 & 5 & 5 & $1.35 \%$ & $2.91 \%$ \\
\hline Late & 944 & 470 & 7 & 7 & $0.74 \%$ & $1.49 \%$ \\
\hline Final & 932 & 471 & 10 & 10 & $1.07 \%$ & $2.12 \%$ \\
\hline Total & 2576 & 1269 & 23 & 23 & $0.89 \%$ & $1.81 \%$ \\
\hline
\end{tabular}

ID: injured individuals. 
Initial Jomon :

(1) Kamikuroiwa Iwakage site

Middle Jomon : -

(2) Miyano shell midden

(3) Aoshima shell midden

(4) Takanekido shell midden

(5) Tsubue Funamoto shell midden

\section{Late Jomon : A}

(6) Kasoriminami shell midden

(7) Fuyuki A shell midden

(8) Shimo Numabe shell midden

(9) Hegi cave

Final Jomon :

(10) Sanganji shell midden

(11) Ikawazu shell midden

(12) Hobi shell midden

(13) Fukahori site

(13)

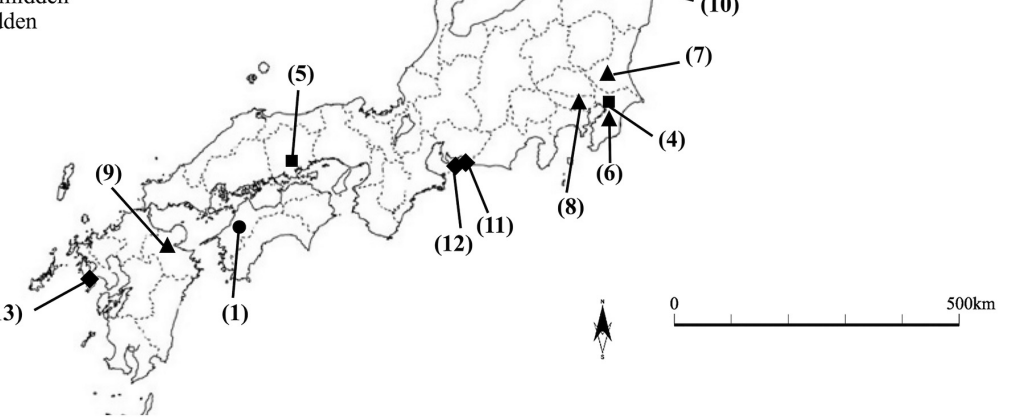

Figure 20.2 Sites with injured skeletal remains in the Jōmon period.

Table 20.3 Estimates of mortality attributable to violence over the Yayoi period (see also Nakagawa et al., 2017)

\begin{tabular}{|c|c|c|c|c|c|c|}
\hline Phase & Total & Adults & ID & $\begin{array}{l}\text { ID without } \\
\text { children }\end{array}$ & ID/total (\%) & $\begin{array}{l}\text { ID without } \\
\text { children/adults(\%) }\end{array}$ \\
\hline Incipient & 27 & 25 & 6 & 6 & $22.22 \%$ & $24.00 \%$ \\
\hline Early & 233 & 156 & 7 & 7 & $3.00 \%$ & $4.49 \%$ \\
\hline Middle & 2,347 & 1,794 & 70 & 66 & $2.98 \%$ & $3.68 \%$ \\
\hline Late & 691 & 420 & 17 & 17 & $2.46 \%$ & $4.05 \%$ \\
\hline Total & 3298 & 2395 & 100 & 96 & $3.03 \%$ & $4.01 \%$ \\
\hline
\end{tabular}

ID: injured individuals.

climate change over this period did not lead to an increase in violence and the Jōmon case, therefore, stands as a counterexample to previous claims that climate change and warfare have been closely connected (e.g., Ember and Ember, 1992; Hsiang et al., 2011; Keeley, 1996; Meyer et al., 2015; Otterbein, 2004; Scheffran et al., 2012; Zhang et al., 2007). Combined with other chapters in this volume, this conclusion deserves considered attention from the human security field, which has for decades argued a strong relationship between climate changes, resource scarcity and competition, and increased migration or violent interaction (see Robbins Schug et al., 2019). 


\section{H. Nakao et al.}

\section{Closer examination of some examples}

The broad pattern of bioarchaeological data suggests climate change was not relevant to the frequency of violent conflict in the Jōmon period. By focusing on some important sites, this section aims to provide additional perspectives for considering the effect of climate on violence. First, we look at sites chronologically close to the catastrophic event at the end of the Middle Jōmon. If climate change promoted violent behavior in the Jōmon period, we should expect to find this effect more clearly when the climate cooled from the late phase of the Middle Jomon to the early phase of the Late Jomon. Indeed, the rate of injured skeletal remains is slightly higher for the Middle Jōmon than for other sub-periods; however, sites with injured skeletal remains are spatially dispersed and no sites have multiple injured skeletal remains except for the Aoshima shell midden in Miyagi Prefecture, which extended mainly from the Middle to the Late Jōmon sub-periods. A total of 25 skeletal remains were found at that site, including two suspected cases of violent injury: an adult male and female with stone projectile points around the thorax and ilium, respectively (Editorial Committee for the History of Minamikata Town, 1975). We have no further evidence to link such a slight increase in the rate of injury to a cooling climate.

It should also be noted that there are sites with significant numbers of skeletal remains but no evidence of violence in the early phase of the Late Jōmon. The Kitamura site in Nagano Prefecture and the Nakazuma shell midden in Ibaraki Prefecture have 190 and around 100 skeletal remains, respectively, belonging to the early phase of the Late Jomon sub-period (Archaeological Research Center of Nagano Prefecture, 1993; Nakazuma Kaizuka Hakkutsu Chosadan, 1995; Suzuki and Suzuki, 1979). Although preservation of the bones at Kitamura is poor, no injured individuals were found. Pit A at Nakazuma, which contained the bones of about 100 individuals, is estimated to have been made more than 200 years after the abandonment of large settlements in the area (Matsumoto 2018a). It was a secondary burial containing mostly skulls and long bones, and no signs of trauma have been reported. Thus, based on the above evidence, it is unlikely that climate change from the late phase of the Middle Jomon resulted in violent conflict.

Second, we examine sites of the Final Jomon sub-period, when the largest number of injured skeletal remains are observed. It has been inferred that repeated cooling occurred during the Final Jōmon (Imamura and Fujio, 2009), which may explain the low population density in eastern Japan. Seven injured skeletal remains have been found at the Ikawazu midden on the Atsumi Peninsula in Aichi Prefecture (e.g., Atsumi Town Board of Education, 1995; Tahara City Board of Education, 2017; Team for Excavation of Ikawazu Site, 1988). This is the largest number of injured individuals known for any site in the Jōmon period. One other injured individual has been found at the Hobi shell midden, located on the same peninsula. Many skeletal remains are known for the Atsumi Peninsula from sites of this time-at Yoshigo, Ikawazu, and Hobi-suggesting a relatively high population density in the area. This is also indicated by the number of contemporaneous sites on the peninsula, which as seen in Table 20.4 are more numerous for the Late and Final Jōmon than in previous sup-periods (Tahara City Board of Education, 2017). While more work is needed to test the hypothesis, the cooling climate in the Late and Final Jomon possibly promoted tidal flats to form; these are rich in shellfish, which is a valuable food source. This environmental change may have promoted a population increase on the peninsula, and the high population density, in turn, may have triggered violent conflicts. Although a more detailed examination of the environmental and social contexts is needed to understand the precise relationship between putative climatic, environmental, and 
Table 20.4 Numbers of sites on the Atsumi Peninsula used in the Jōmon period. Thick lines indicate "probably used" and dotted lines "possibly used" (based on Tahara City Board of Education, 2017).

\begin{tabular}{|c|c|c|c|c|c|c|c|}
\hline \multicolumn{2}{|r|}{ Phase } & Incipient ! & Initial & Early & Middel & Late & Final \\
\hline 遺跡名 & Site & & & & $\mathrm{I}$ & & \\
\hline 保美貝塚 & Hobi shell midden & & & & & & \\
\hline 長代貝塚 & Nagashiro shell midden & & & & & & \\
\hline 宮西貝塚 & Miyanishi shell midden & & & & & & \\
\hline 雁合貝塚 & Gango shell midden & & & & & & \\
\hline 山崎遺跡 & Yamasaki site & & & & & & \\
\hline 吉胡貝塚 & Yoshigo shell midden & & & & & & \\
\hline 伊川津貝塚 ! & Ikawazu shell midden & $\mid$ & & & & & \\
\hline 青津前田遺跡， & Aotsumaeda site & T & & & & & \\
\hline 平野貝塚 ! & Hirano shell midden & I & & & & i & 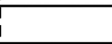 \\
\hline 北屋敷貝塚 & Kitayashiki shell midden & T & & & & & 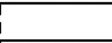 \\
\hline 川地貝塚 & Kawaji shell midden & T & & & & & \\
\hline 八幡上貝塚 & Hachimanue shell midden & T & & & T & & \\
\hline 籠田遺跡 & Kas sta site & & & & T & & \\
\hline 西南代遺跡 | & Nisnınandan site & $T$ & & & T & 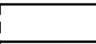 & 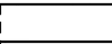 \\
\hline 下地貝塚 & Shimoji shell midden & i & & & & 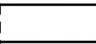 & \\
\hline 羽根貝塚 & Hane shell midden & i & & & 1 & & \\
\hline 佐藤遺跡 & Sato site & I & & & 1 & 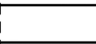 & 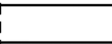 \\
\hline 黒河遺跡 & Kurokawa site & I & & & 1 & 5 & \\
\hline 清水遺跡 & Shimizu site & it & & & 1 & 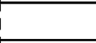 & \\
\hline 下畑遺跡 & Shimohata site & i & & & 1 & 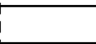 & \\
\hline 田原城惣門跡； & Tawarajo somon site & 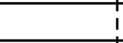 & & & 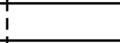 & & \\
\hline 柏坪遺跡 & Kashiwatsubo site & + & & & $i$ & & \\
\hline 小今口遺跡 | & Koimaguchi site & 1 & & & $!$ & & \\
\hline 坂井戸遺跡 & Sakaido site & & & & I & & \\
\hline 比留輪原 & Hiruwabara & + & & & 1 & 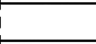 & \\
\hline & Max. & 10 & 5 & 3 & 3 & 9 & 17 \\
\hline & Min. & 9 & 5 & 3 & 3 & 7 & 8 \\
\hline
\end{tabular}

social changes, it is remarkable that evidence for violence on the Atsumi Peninsula remained low, with only eight injured individuals among 514 skeletal remains in total.

Summing up, although there remains a possibility that climate change increased social tensions in the Late and Final Jōmon in some way, no evidence suggests increased violence. It is also unlikely that the relatively high rate of injured skeletal remains in the Middle Jōmon period could be explained in terms of climate change. Nor do we find evidence for an effect of climate change on violence during other sub-periods. Accordingly, in contrast with previous studies arguing that climate change can promote violent behavior such as warfare, we conclude that climate change had a limited influence-if any-on violence in the Jömon period.

\section{Discussion}

There are some limitations to using bioarchaeological data to test the assertion that climate change and violent conflict are related. We have argued that since the rate of violent conflict was stable during the Jōmon period, there is no association between climate change and increased violent interactions. Note that our claim is based on a lack of evidence, which cannot conclusively prove a lack of violent behavior. Future evidence for violence, such as discoveries of 


\section{H. Nakao et al.}

additional evidence for injuries in skeletal remains, could challenge the argument made in this chapter. Moreover, a possible bias should be noted for the bioarchaeological data set, because human skeletal remains are more vulnerable to soil conditions than other material remains; in other words, the data do not directly reflect the actual population of the time. Further empirical and theoretical studies are required to reconstruct past societies from bioarchaeological data.

Second, if climate change had no significant effect on violent behavior in the Jōmon period as we assert, we need to ask why. One possible answer is that they managed conflicts without resorting to violence (e.g., Matsumoto, 2018b). Ethnographic data show many cultural mechanisms for avoiding violent conflict, such as instilling values that abhor physical violence and coercion in favor of nurturance and affiliation (Dentan, 1968, 2008; Miklikowska and Fry, 2010; Robarcheck, 1977). It has also been reported that some hunter-gatherers tend to hide from potential opponents and thereby avoid violent conflict (e.g., Marlowe, 2010; Nakao, 2015; Nakao and Machery, 2012). Although it is difficult to infer such cultural values or practices based on archaeological data, ritualistic objects found at Middle Jōmon sites in the Chubu and Kanto regions, consisting of female figurines, miniature pottery, and highly decorated pottery, seem to focus on women, production, and reproduction (Matsumoto, 2011). Also, fissioning of villages has been reported as a cultural mechanism for limiting the occurrence of violence among the Hopi of Northern Arizona (Schlegel, 2004). The abandonment of large settlements at the end of the Middle Jommon, followed by a period of smaller, scattered settlements in the eastern part of the Japanese archipelago (Imamura, 1997; Kanno, 2017), may indicate the management of economic and social stress by a similar fissioning of villages. The representations of figurines change from the Middle Jōmon to the Late Jōmon, probably indicating that adjustment at a symbolic level also occurred (Ikawa-Smith, 2002). Further examinations of the relevant data are needed, however, for assessing these or other possible reasons.

\section{Conclusion}

This chapter reviewed research on the effects of climate change on Jōmon society and culture. The summary suggests that climate change affected culture and society in many ways, especially around the Middle Jōmon sub-period. Also, we summarized the bioarchaeological data for the Jomon and Yayoi periods and argued that climate change did not promote violent conflict in the Jomon period. Further investigations on regional diversity in the effects of climate change on violence, or diversity in strategies for responding to resource scarcity in Jōmon society, may be fruitful for enhancing our understanding of the interrelationships between climate change and human responses.

\section{Acknowledgments}

This work is supported by the following grants from the Japan Society for the Promotion of Science: "Integrative studies of anthropological, archaeological, and cognitive evidence through a 3D database construction and mathematical analyses and modeling" (Grant-in-Aid for Scientific Research on Innovative Areas (Research in a proposed research area), JP19H05738) to H.N. and K.T., "Integrative Human Historical Science of 'Out of Eurasia': Exploring the Mechanisms of the Development of Civilization" (Grant-in-Aid for Scientific Research on Innovative Areas (Research in a proposed research area), JP19H05731) to H.N., N.M., and T.M., "Philosophical investigation of theory and practice in archaeology: Toward a philosophy of humanities" (Grant-in-Aid for Encouragement of Young Scientists (B), JP16K16685) to H.N., "Mathematical analysis of historical and regional variations of iron projectile points in the 
Kofun period" (Grant-in-Aid for Scientific Research on Innovative Areas (C), JP17K03226) to H.N., K.T., and T.M., Research Fellowship for Young Scientists (DC2, No. 18J13015) to T.N., and "Constructing synthetic research environment for archaeological data" (Grant-in-Aid for Early-Career Scientists, JP18K18325) to K.T. Other support came from Suntory Foundation Research Grants. We also thank Takamune Kawashima for useful comments on an earlier draft.

\section{References}

Abe, A. (2008). Social Change in the Jōmon Period. Tokyo: Um Promotion (in Japanese).

Anzai, M. (2014). Climate Change and Changes of Jōmon Culture. Tokyo: Doseisha (in Japanese).

Archaeological Research Center of Nagano Prefecture. (1993). The Kitamura Site. Nagano, Nagano Prefecture (in Japanese).

Atsumi Town Board of Education (Ed.) (1995). The Ikawazu Site, Excavation of 1992. Atusmi Town, Aichi Prefecture (in Japanese).

Bowles, S. (2009). Did warfare among ancestral hunter-gatherers affect the evolution of human social behavior? Science, 324, 1293-1298.

deMenocal, P.B. (2001). Cultural responses to climate change during the Late Holocene. Science, 292, 667-673.

Dentan, R.K. (1968). The Semai: A Nonviolent People of Malaya. New York: Holt, Rinehart and Winston.

Dentan, R.K. (2008). Overwhelming Terror: Love, Fear, Peace, and Violence Among Semai of Malaysia. Lanham, MD: Rowman \& Littlefield.

Douglas, P.M.J., Pagani, M., Canuto, M.A., Brenner, M., Hodell, D.A., Eglinton, T.I., \& Curtis, J.H. (2015). Drought, agricultural adaptation, and sociopolitical collapse in the Maya lowlands. Proceedings of the National Academy of Sciences, 112(18), 5607-5612.

Editorial Committee for the History of Minamikata Town. (1975). Report on the Aoshima Shell Midden of Minamikata Town, Tome-gun, Miyagi Prefecture. Minamikata town, Miyagi Prefecture (in Japanese).

Ember, C.R., \& Ember, M. (1992). Resource unpredictability, mistrust, and war: A cross-cultural study. Journal of Conflict Resolution, 36, 242-262.

Fujimoto, K. (1990). Late Holocene Sea-Level Change in the Japanese Archipelago. Ph.D. thesis submitted to Tohoku University (in Japanese).

Habu, J. (2004). Ancient Jōmon of Japan. New York: Cambridge University Press.

Habu, J. (2008). Settlement growth and decline in complex hunter-gatherer societies: A case study from the Jōmon period Sannai Maruyama site. Antiquity, 82, 571-584.

Habu, J. (2017). Food the environment in the Jomon Period. Kagaku, 87(2), 0154-0157 (in Japanese).

Habu, J., \& Hall, M.E. (2013). Climate change, human impacts on the landscape, and subsistence specialization: Historical ecology and changes in Jōmon hunter-gatherer lifeways. In V.D. Thompson \& J.C. Waggoner (Eds.), The Archaeology and Historical Ecology of Small-Scale Economies (pp. 65-78). Gainesville: University Press of Florida.

Hashiguchi, T. (2007). Warfare in the Yayoi Period: The Picture of Warfare and the Emergence of Power Structure. Tokyo: Yuzankaku (in Japanese).

Hayden, B. (1995). Pathways to power: Principles for creating socioeconomic inequalities. In T.D. Price \& G. Feinman (Eds.), Foundation of Social Inequality (pp. 15-85). New York: Plenum.

Hitoki, E. (2012). Marine Environment and Human Activity During the Jōmon Transgression in Japan. Ph.D. thesis submitted to The University of Tokyo (in Japanese).

Hoggath, J.A., Breitenbach, S.F.M., Culleton, B.J., Ebert, C.E., Masson, M.A., \& Kennett, D.J. (2016). The political collapse of Chichén Itzá in climatic and cultural context. Global and Planetary Change, $138,25-42$.

Hsiang, S.M., Meng, K.C., \& Cane, M.A. (2011). Civil conflicts are associated with the global climate. Nature, 476, 438-441.

Ikawa-Smith, F. (2002). Gender in Japanese prehistory. In S.M. Nelson and M. Rosen-Ayalon (Eds.), In Pursuit of Gender: Worldwide Archaeological Approaches (pp. 323-354). Walnut Creek, CA: AltaMira Press.

Imamura, K. (1997). The number of dwellings and population dynamics in the Jōmon period. In T. Fujimoto (Ed.), Archaeology of Dwellings (pp. 45-60). Tokyo: Doseisha (in Japanese).

Imamura, K. (2000). Prehistoric Japan: New Perspectives on Insular East Asia. New York: Routledge. 


\section{H. Nakao et al.}

Imamura, M., \& Fujio, S. (2009). Historical variations of natural environments based on the record of carbon-14. In H. Shitara, S. Fujio, \& T. Matsugi (Eds.), The Birth of the Yayoi Culture (Archaeology of the Yayoi period vol. 2). Tokyo: Doseisha (in Japanese).

Intergovernmental Panel on Climate Change. (2013-2014). Fifth assessment report (AR5). URL: www. ipcc.ch/report/ar5/.

Kanno, T. (2017). Jōmon culture in the eastern part of Japan. In Y.Yamada (Ed.), The Jōmon Period: How Should we Understand its Framework, Culture, and Society? (pp. 70-89). Tokyo: Yoshikawa Kobunkan (in Japanese).

Kawahata, H., Ishizaki, Y., Kuroyamagi, A., Suzuki, A., \& Ohkushi, K. (2017). Quantitative reconstruction of temperature at a Jōmon site in the incipient Jōmon period in northern Japan and its implications for the production of early pottery and stone arrowheads. Quaternary Science Reviews, 157(1), 66-79.

Keeley, L.H. (1996). War Before Civilization: The Myth of the Peaceful Savage. New York: Oxford University Press.

Kodama, D. (2003). Komakino stone circle and its significance for the study of Jomon social structure. In J. Habu, J.M. Savelle, S. Koyama, \& H. Hongo (Eds.), Hunter-gatherers of the North Pacific Rim. Senri Ethnological Studies, 72, 235-261.

Kosugi, Y., Taniguchi,Y., Nishida,Y., Mizunoe, K., \& Yano, K. (2009). The Land and Forests: Palaeoecology in the Jommon Period (Archaeology of the Jōmon Period Vol. 3). Tokyo: Doseisha (in Japanese).

Kosugi, Y., Taniguchi, Y., Nishida, Y., Mizunoe, K., \& Yano, K. (2010). The Interaction Between Humans and Animals: Diet and Subsistence System (Archaeology of the Jomon period Vol. 4). Tokyo: Doseisha (in Japanese).

Koyama, S. (1978). Jōmon subsistence and population. Senri Ethnological Studies, 2, 1-65.

Koyama, S. (1984). The Jōmon period. Tokyo: Chuo Koronsha (in Japanese).

Kudo,Y. (2012). Environmental and Culture History of the Upper Palaeolithic and the Jomon Period: High-Precision Radiocarbon Dating and Archaeology. Tokyo: Shinsensha (in Japanese).

Marlowe, F. (2010). The Hadza: Hunter-Gatherers of Tanzania. Berkeley: University of California Press.

Matsugi, T. (2007). Warfare and the Initial State Formation in the Japanese Archipelago. Tokyo: The University of Tokyo Press (in Japanese).

Matsugi, T. (2017). Why Do Humans Have War? Archaeology of Warfare. Tokyo: Chuokoron-Shinsha (in Japanese).

Matsui, A. (2005). An Invitation to Environmental Archaeology. Tokyo: Iwanami Shoten (in Japanese).

Matsumoto, N. (2011). Figurines, circular settlements and Jōmon worldviews. In A. Cannon (Ed.), Structured Worlds: The Archaeology of Hunter-Gatherer Thought and Action, (pp.168-182). Sheffield: Equinox.

Matsumoto, N. (2018a). Changing relationship between the dead and the living in Japanese prehistory. Philosophical Transactions of the Royal Society B, 373(1754), 20170272.

Matsumoto, N. (2018b). Warfare among hunter-gatherer societies: Considering promoting/preventive factors of inter-group violence. Quarterly of Archaeological Studies, 65(3), 22-36 (in Japanese).

Matsumoto, N., Habu, J., \& Matsui, A. (2017). Subsistence, sedentism, and social complexity among Jōmon hunter-gatherers of the Japanese archipelago. In J. Habu, P.V. Lape, \& J.W. Olsen (Eds.), Handbook of East and Southeast Asian Archaeology (pp. 437-450). New York: Springer.

Meyer, C., Lohr, C., Gronenborn, D., \& Alt, K.W. (2015).The massacre mass grave of Schöneck-Kilianstädten reveals new insights into collective violence in early Neolithic central Europe. Proceedings of the National Academy of Sciences, 112(36), 11217-11222.

Miklikowska, M. \& Fry, D.P. (2010).Values for peace: Ethnographic lessons from the Semai of Malaysia and the Mardu of Australia. Journal of Beliefs and Values, 2(2), 124-137.

Morisaki, K., Izuho, M., Terry, K., \& Sato, H. (2015). Lithics and climate: Technological responses to landscape change in Upper Palaeolithic northern Japan. Antiquity, 345(89), 554-572.

Morisaki, K., Izuho, M., \& Sato, H. (2018). Human adaptive responses to environmental change during the Pleistocene-Holocene transition in the Japanese archipelago. In E. Robinson \& F. Sellet (Eds.), Lithic Technological Organization and Paleoenvironmental Change: Global and Diachronic Perspectives (pp. 91-122). New York: Springer.

Nakagawa, T. (2020). Cultural Context in Prehistoric Violence. Ph.D. thesis submitted to Okayama University (in Japanese).

Nakagawa, T., Nakao, H., Tamura, K., Arimatsu,Y., Matsumoto, N., \& Matsugi, T. (2017).Violence and warfare in prehistoric Japan. Letters on Evolutionary Behavioral Science, 8(1), 8-11.

Nakagawa, T., Nakao, H., Tamura, K., Yamaguchi,Y., Matsumoto, N., \& Matsugi, T. (2019). Prehistoric warfare in the middle phase of the Yayoi period in Japan: Human skeletal remains and demography. Journal of Computer Archaeology, 24(1/2), 10-29 (in Japanese). 
Nakagawa, T., Nakao, H., Tamura, K., Yamaguchi, Y., Matsumoto, N., \& Matsugi, T. (n.d.). Population pressure and prehistoric violence in the middle Yayoi period of Japan. [Manuscript in preparation]

Nakao, H. (2015). Philosophy of Human Evolution: Behavior, Mind, and Culture. Nagoya: University of Nagoya Press (in Japanese).

Nakao, H., \& Machery, E. (2012). The evolution of punishment. Biology and Philosophy, 27(6), 833-850.

Nakao, H., Tamura, K., Arimatsu, Y., Nakagawa, T., Matsumoto, N., \& Matsugi, T. (2016). Violence in the prehistoric period of Japan: The spatiotemporal pattern of skeletal evidence for violence in the Jomon period. Biology Letters, 12, 20160028.

Nakazuma kaizuka hakkutsu chosadan. (1995). Excavation Report of the Nakazuma Site. Toride: Toride City Board of Education (in Japanese).

Okada, Y. (2003). Jōmon culture of Northeastern Japan and the Sannai Maruyama site. In J. Habu, J.M. Savelle, S. Koyama, \& H. Hongo (Eds.), Hunter-gatherers of the North Pacific Rim. Senri Ethnological Studies, 72, 173-186.

Otterbein, K.F. (2004). How War Began. College Station: Texas A\&M University Press.

Pinker, S. (2011). The Better Angels of our Nature: Why Violence has Declined. New York: Viking.

Robarchek C.A. (1977). Frustration, aggression, and the nonviolent Semai. American Ethnologist, 4(4), 762-779.

Sahara, M. (1986). Cattles, slaves, kingly tombs and warfare: Japan in the world. Rekishi Kagaku, 103, 1-17 (in Japanese).

Sasaki, F. (2000). Reconstruction of the image of the Jōmon society. Ibou, 18, 88-107 (in Japanese).

Sato, H., Izuho, M., \& Morisaki, K. (2011). Human cultures and environmental changes in the PleistoceneHolocene transition in the Japanese archipelago. Quaternary International, 237(1-2), 93-102.

Scheffran, J., Brzoska, M., Kominek, J., Link, P.M., \& Schilling, J. (2012). Climate change and violent conflict. Science, 336, 869-871.

Schlegel, A. (2004). Contentious but not violent: The Hopi of Northern Arizona. In G. Kemp \& D. Fry (Eds.), Keeping the Peace: Conflict Resolution and Peaceful Societies around the World (pp. 19-34). London: Routledge.

Smith, F.A., Smith, R.E.E., Lyons, S.K., \& Payne, J.L. (2018). Body size downgrading of mammals over the late Quaternary. Science, 360, 310-313.

Suzuki, M., \& Suzuki, K. (Eds.) (1979). Toride and its Prehistory: Studies on Nakazuma Shell Midden. Ibaragi, Toride city (in Japanese).

Suzuki, S. (2005). Holocene Sea-level Change and Tertonic Subsidence in Okayama Plain. Oral presentation, Chushikoku branch meeting, Japan Society ffE rgineering Geology (in Japanese).

Tahara City Board of Education (Eds.) (2017). Hobı snell Midden: A Large Shell Midden of the Final Phase of the Jōmon Period at the Atsumi Peninsula (Tahara City Reports on Buried Cultural Property No. 11). Aichi, Tahara City (in Japanese).

Taniguchi,Y. (2017). Social Complication and Rituals in the Jōmon Period. Tokyo: Doseisha (in Japanese)

Team for Excavation of Ikawazu site (Ed.) (1988). The Ikawazu Site. Atsumi Town Board of Education, Aichi Prefecture (in Japanese).

Tomioka, N. (2010). Paleoceanography, ichthyofaunal, and malacofauna in the Jōmon period. In Y. Kosugi, Y. Taniguchi, Y. Nishida, K. Mizunoe, \& K. Yano (Eds.), The Interaction Between Humans and Animals: Diet and Subsistence System (Archaeology of the Jōmon period Vol. 4) (pp. 23-37). Tokyo: Doseisha (in Japanese).

Tsuji, S. (2009). Vegetation in the Jōmon period. In Y. Kosugi, Y. Taniguchi, Y. Nishida, K. Mizunoe, \& K. Yano (Eds.), The Land and Forests: Palaeoecology in the Jömon Period (Archaeology of the Jōmon Period Vol. 3) (pp. 67-77) Tokyo: Doseisha (in Japanese).

Uetsuki, M. (2010). Marine fishes in the Jōmon period. In Y. Kosugi,Y.Taniguchi,Y. Nishida, K. Mizunoe, \& K.Yano (Eds.), The Interaction Between Humans and Animals: Diet and Subsistence System (Archaeology of the Jomon Period Vol. 4) (pp. 91-103) Tokyo: Doseisha (in Japanese).

Watanabe, H. (1990). Jōmon Stratified Society. Tokyo: Rokko Shuppan (in Japanese).

Yamada, Y. (2006). Burials in the Jōmon period: Based on examples of buried bones. Jōmon Jidai, 17, 73-192 (In Japanese).

Yasuda, Y. (1989). The growth and decline of the Indus civilization and the Jomon culture. Bulletin of International Research Center for Japanese Studies, 1, 205-272 (in Japanese).

Zhang, D.D., Brecke, P., Lee, H.F., He, Y.-Q., \& Zhang, J. (2007). Global climate change, war, and population decline in recent human history. Proceedings of the National Academy of Sciences, 104(4), 19214-19219. 


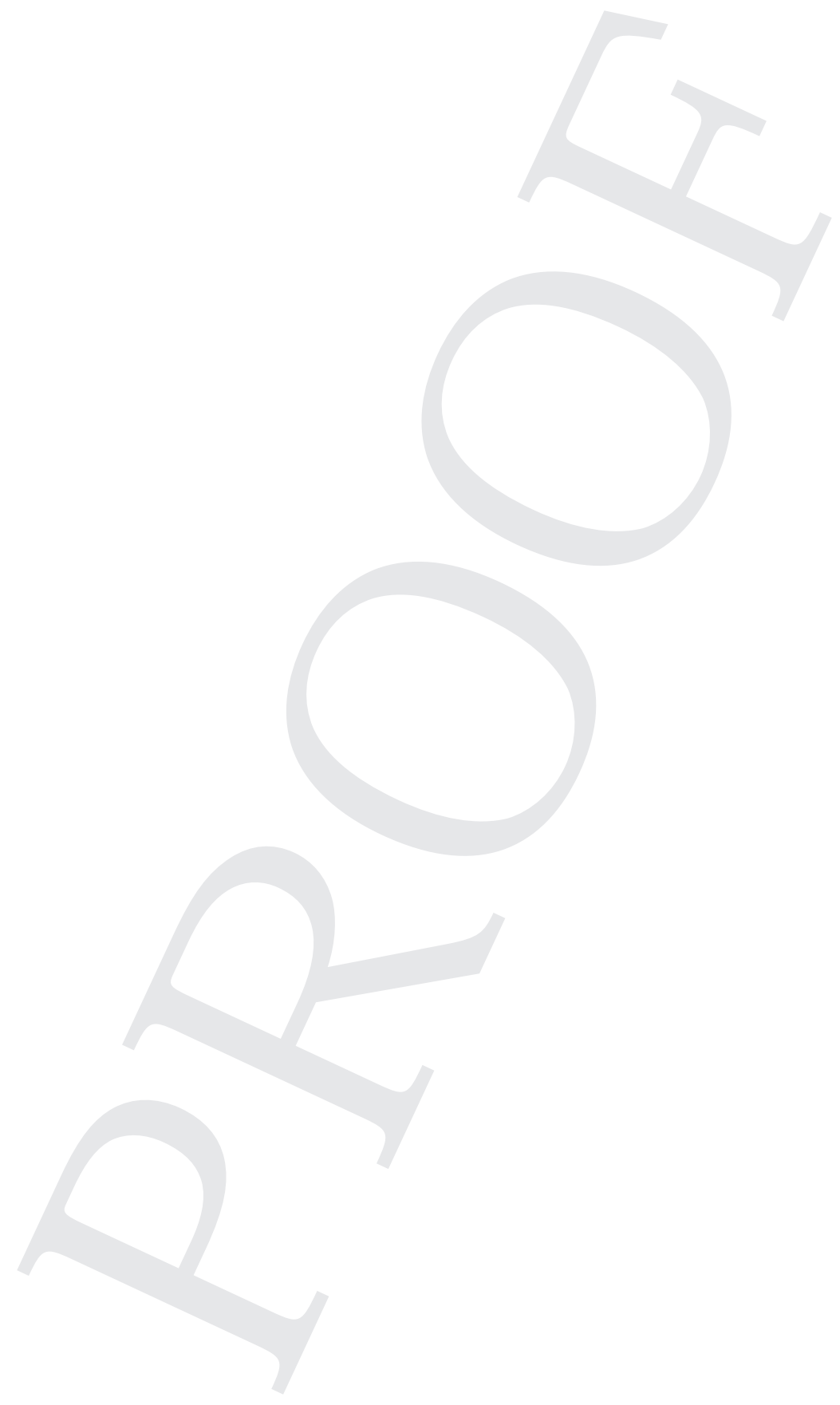

9781138492486_pi-510.indd 376

04-Jul-20 5:27:04 PM 